\title{
Remote Farm Monitoring and Irrigation System
}

\author{
Zena N. Faysal \\ zena.csp80@student.uomosul.edu.iq \\ Ghassan J. Mohammed \\ ghassan.j.m.aladool@uomosul.edu.iq \\ Department of Computer Science, \\ College of Computer Science and Mathematics, \\ University of Mosul, Mosul, IRAQ
}

Received on: 01/02/2021

Accepted on: 09/03/2021

\begin{abstract}
The research deals with the intelligent irrigation system using the Internet of Things (IoT) via Low cost and low power system on chip microcontrollers including integrated Wi-Fi with dual-mode Bluetooth ESP32. The objectives of this project are to investigate the concept of an intelligent irrigation system using the Internet of Things, to develop a system using the aforementioned controller that processes data from the soil sensor that automatically irrigates the plant and analyzes the soil status of the plants. In real-time via the smartphone connected to the Internet. The study scope focuses on cropping and horticulture. Sensors had to be installed for each plant as it was necessary to know the condition of the soil. A water pump must also be added to each plant to save water. This project requires the Blynk application which is a platform with IOS and Android apps to control Arduino, Raspberry Pi and the likes over the Internet. It's a digital dashboard where you can build a graphic interface for your project by simply dragging and dropping widgets. Software on smartphone and hardware implementation which can detect environment condition using (DHT22: Temperature and Humidity sensor) sensor and soil moisture sensor. The results of this paper are based on the experiments performed.
\end{abstract}

Keywords: IoT, smartphone, sensor, blynk app

\section{Introduction}

As commonly known, a connection between climate policies and water management, the probable global warming consequences led to a reconsideration of water adaptation procedures to ensure the water is available for people and for food production for maintaining ecosystems [1].

Also, the issue of the safety of the water consumed by humans and returned to the environment should be ensured. The possible dangers of climate change are caused in the following: water shortage, biodiversity loss, soil salinity, reduction of water quality, the increasing requirements in irrigation, high possible cost because of procedures of emergency and remediation. As a result, many studies aiming to control water usage in irrigation have been made; some of them deal with adopting social, economic and climate change policies. They also explain the role of technology in improving water management [2].

Taking into consideration that the commercial sensors-based system used in agriculture and irrigation is very expensive, smaller farmers are unable to use this system in their farms. Nevertheless, manufacturers are offering low-cost sensors embedded in the nodes to be used for managing irrigation and monitoring agriculture.

Furthermore, because of the increasing interest in low-cost sensors for monitoring water and agriculture, many kinds of these sensors are suggested by many researchers, such as 
a sensor of leaf water stress monitoring [4], a sensor of multi-level soil moisture that consists of copper rings which are placed alongside a PVC pipe [5], a sensor for monitoring water salinity which is made of copper coils [6] or sensor of water turbidity that is made of infrared and coloured led.

Recent advancements in applications, the new emerging used in the irrigation systems led the WSN and IoT technologies to be applied in the development of these systems.

\subsection{Internet of Things}

The term "IoT" is the abbreviation of the Internet of Things, which could be defined as the interconnection between the individual identifiable embedded computing apparatus in the internet access infrastructure. Various devices are connected by IoT transportations using the internet and electronic sensors. As shown in Figure 1 [7].

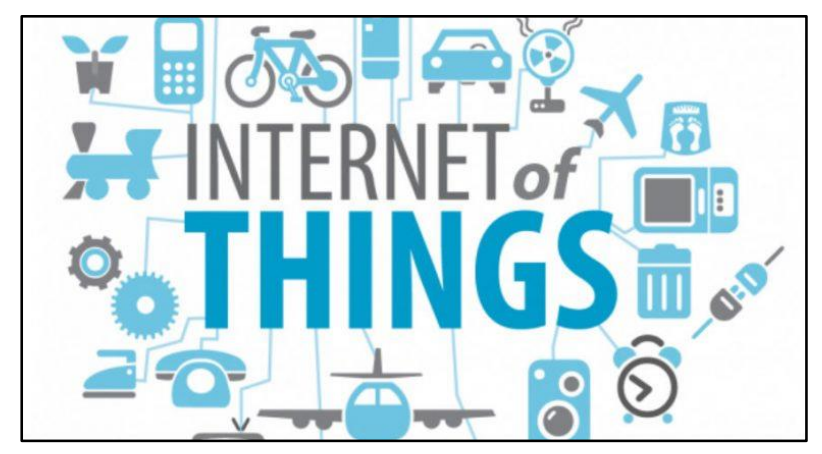

Figure 1: Internet of Things Infrastructure

As another description of IoT, it is the physical objects network "things" that are built-in with software, sensors, and many other technologies to connect and exchange data with devices and systems over the Internet [1-4].

IoT is evolved as a result of the interchange of multiple technologies, such as machine learning, commodity sensors, real-time analytics and embedded systems [1].

The traditional field of embedded systems, networks of wireless, automation (home and building automation), control system and many others enable the IoT. In the market, IoT technology is synonymous with products related to the concept of the "smart home", including devices such as thermostats, lighting fixtures, systems of home security and cameras, and many others, which support common ecosystems, and could be controlled through devices related to that ecosystem, such as smart speakers and smartphones [4].

However, there are concerns regarding dangers in the growth of IoT particularly that is associated with security and privacy which promote industry and governments actions to address these concerns by including the development of international standards.

\subsection{Literatures Review}

The sensors in which Smartphone is used for capturing and processing soil images are represented by Joaquin Gutierrez et al in 2015. An image is captured to evaluate the water content of the soil. The router node is used for collecting values to the gateway providing an automatically pump of the water to a field. In this work, an android app is used for connection, such as Wi-Fi. Through using the given parameters, the Android application will wake up the Smartphone. Then, an RGB picture of the soil is taken by in-built cameras via an anti-reflective glass window to estimate the wet and dry area. 
The mobile application makes the Wi-Fi connection of the Smartphone transmit the estimated value to the gate using a router node for controlling a water pump for irrigation [8].

A design of a smart sprinkler system that is using mesh having WSN for monitoring and controlling irrigation system for a field is represented by T.C.Meyer et al. in 2015. The system gives accuracy by controlling the level of soil moisture among the thresholds. Data is sent by sensor nodes to the base station each time. The base station includes an actuator interface for controlling the solenoid valve by using GUI providing system feedback to users and allowing the change of the parameter and, at first, setup the system. For example, the tomato crop is influenced greatly by air and soil temperature, and humidity. Many diseases, such as leaf mound, affects tomato crop because of high humidity and warm temperature, then it is needed like this system [9].

In 2019, Diana Rwegasira Josephat Kalezhi proposed a system of manageable and smart DC microgrid watering using multi-operator frameworks with IoT enabled sensors for agricultural irrigation. A low-cost and widely used system utilizing solarpowered water pumping are presented by using water tanks PV panels, and water pipes which can be utilized for building an irrigation system. design a load shedding algorithm for an irrigation system building. An agent-based algorithm organizes the energy demand of the PV system and controlling irrigation is also introduced. Collected data from sensor nodes are sequentially transmitted over LoRA (Long Range Radio) towards a sink node. The automated monitoring using sensors is enabling the controlled use of resources of limited water. As transmission technologies, ZigBee and LoRa are used for good communication ranges [10].

In 2019, research-based on Smart Irrigation System is proposed by researchers. They introduced a brief explanation of some applications that are based on IoT for minimizing crop loss during and after harvest using sensors and Raspberry Pi. This proposed system results in various smart affordable and profitable modules for supervising soil moisture that used motor driver, pest sensors, a sensor of wireless moisture, motor alarm, sprinkler, etc. Besides, the pest's intelligent seeds corporation including sensors of motion and humidity, camera Raspberry Pi 3, dehumidifier starter, rodent repellent, etc., and Indian effective food corporation [11].

\section{Theoretical Background}

In this section, all hardware components are explained in details picked from their datasheets and all impotent information of all parts of the system designed.

\subsection{ESP32}

ESP32 is a low-cost series, low-power system on a chip microcontroller having integrated Wi-Fi with dual-mode Bluetooth. The A Tensilica Xtensa LX6 microprocessor in both dual-core and single-core variations are employed by the ESP32 series. ESP32 consists of many parts including built-in antenna switches, RF balun, filters, amplifiers of low-noise receive amplifier and power, and power-management modules [12]. ESP32 is created and developed by Espressif Systems, a Chinese company located in Shanghai created and developed ESP32. Besides, it is manufactured by TSMC by the use of their $40 \mathrm{~nm}$ process [13]. It can be said that ESP32 is a successor to the ESP8266 microcontroller.

The ESP32 represents an upgraded microcontroller of the earlier ESP8266, in ESP32 Bluetooth interface and a faster dual-core processor are added. Figure 2 shows a block diagram for the features that existed inside the ESP32. The ESP32 is often seen as 
being a metal-cased module that is later placed on larger boards having added components. Metal-cased product a flash memory chip, a crystal oscillator, capacitors etc. are included in the metal-cased product [14]. The Metal-cased module, which is considered a major plus: could be included in the new products without the need for further testing.

The key studio ESP32 core board, which brings out most I/O ports for pinning headers of $2.54 \mathrm{~mm}$ pitch, is a mini development board that is based on the ESPWROOM-32 module. These provide an easy way of connecting peripherals according to user needs. As related to develop and debug with the development board, both side standard pin headers can make the operation more efficient. The ESP-WROOM-32 module is the industry's leading integrated WiFi + Bluetooth solution with less than 10 external components. It integrates an antenna switch, RF balun, power amplifiers, low noise amplifiers, filters and power management modules. At the same time, it also integrates with TSMC's low-power 40nm technology, so that power performance and RF performance are safe and reliable, easy to expand to a variety of applications [15].

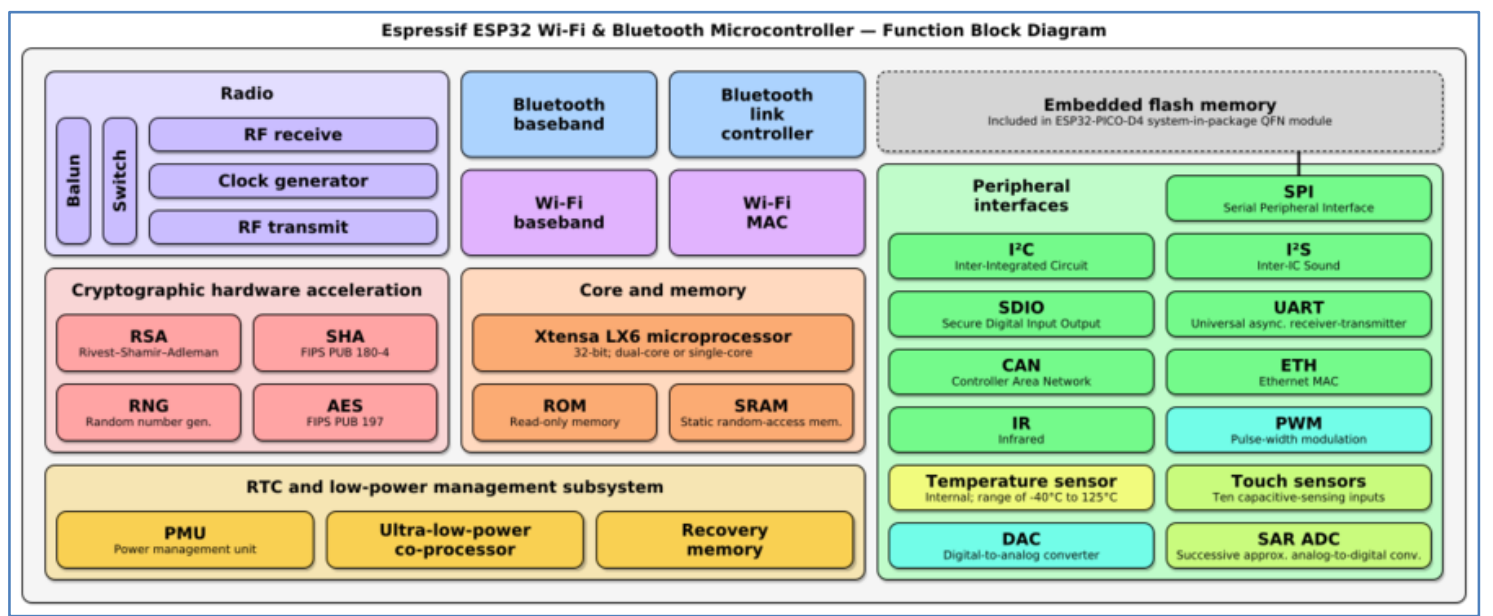

Figure 2: Espressif SEP32 WiFi \& Bluetooth Microcontroller - Function Block Diagram

\subsection{YL-69 Moisture Sensor}

It is an electrical resistance sensor which is consisting of two electrodes. This sensor of soil moisture is reading the moisture content surrounding it. A current is passed towards the electrodes throughout the soil and the soil resistance converted to the current, the soil moisture is determined. When the soil has more water, resistance is low. Consequently, more current would pass through. Moreover, at the time when the soil moisture is low, a high level of resistance is output by the sensor module outputs. This sensor includes both digital outputs and analogue outputs. The first output is easy to use but is not as precise as the second one. The sensor is shown in figure 3 [16].

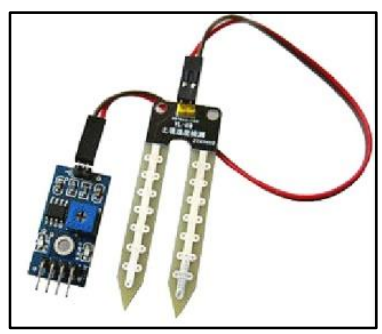

Figure 3: YL-69 Moisture sensor 


\subsection{SSR (Solid State Relay)}

A solid-state relay SSR is an ON-OFF controlling device where the load current is conducted through one or more semiconductors - for example, a TRIAC, a power transistor, an SCR, (The SCR and TRIAC are often known as "thyristors," a term that is derived by combining thyristor and transistor because thyristors are triggered switches of semiconductor.)

\subsection{SSR Heatsink}

Heat Sinks are needed to guarantee the convenient operation and long-range reliability of Solid State Relays since they offer a means for dissipating the power which is commonly generated in the SSR into the around ambient air and maintaining a safe operating temperature. As in Figure 4.

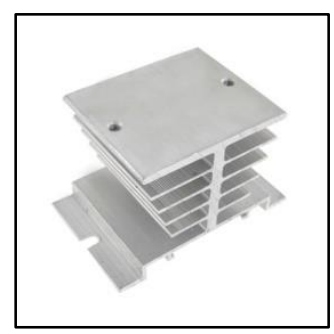

Figure 4: SSR Heat sink

\subsection{Water pump}

Piston and plunger pumps are reciprocating positive displacement pumps in which a piston or plunger is used for moving liquid via a cylindrical chamber. They are also known as high-pressure pumps, well service pumps, or high viscosity pumps since they could transfer high pump pressures and can handle both viscous and solids that contain media. See Figure 5 [18].

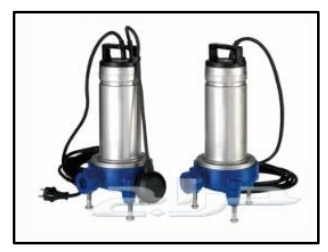

Figure 5: plunger water pump

\subsection{ULN 2003}

ULN2003 IC is one of the most widely used motor drivers IC. This IC is useful while we need to drive high current loads by using circuits of digital logic such as Timers, Gates, Op-maps, Arduino, ARM, PIC, etc. For instance, a motor requiring 9V and $300 \mathrm{~mA}$ to run could not be powered by an Arduino I/O. Hence, this IC is used to source sufficient voltage and current for the load. This IC is widely used for driving Motors, relay modules, high current LEDs, and stepper motors. Figure 6 shows the ULN 2003 IC [19].

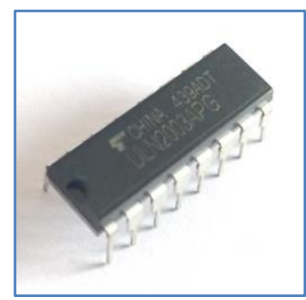

Figure 6: ULN 2003 


\subsection{DC-DC BuCK CONVERTER MOdule 5V 3A}

These boards are adjustable current limiting, fixed 3A current limiting. Before using, it should be made sure that this module within its work range. A short circuit should be output; otherwise, the board will be burnt out. While setting the parameter, it should take into account that output voltage is stable, before the use of the module, to avoid any damage. Besides, the voltage can be adjusted by placing a multimeter on the output, in a synchronous way, by using a screwdriver for adjusting a potentiometer. For obtaining $5 \mathrm{~V}$, it can be adjusted using a small variable resistor as shown in Figure 7.

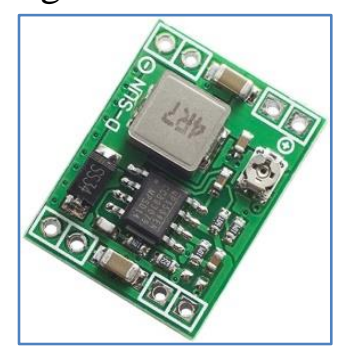

Figure7: 5V-3A Buck Converter

\subsection{TFT 2.2 colour screen}

This breakout display is the best way to display for any project. Because the 2.2inch SPI TFT LCD Color Screen Module display has 4-wire SPI used for communication and has its pixel-addressable frame buffer, it could be used with every type of microcontroller, including a very small microcontroller having few pins and low memory.

The 2.2" display has $176 \times 220$ colour pixels. Like LCDs, which are CSTN kind, thus having slow refresh and poor colour, and unlike the low-cost "Nokia 6110", this display is a true TFT. The TFT driver (ILI9225) could display a fully 18-bit colour (262,144 shades!).

The breakout includes the TFT display that is soldered on (in which a delicate flex-circuit connector is used), a $3 / 5 \mathrm{~V}$ level shifter and an ultra-low-dropout $3.3 \mathrm{~V}$ regulator so it can be used with $3.3 \mathrm{~V}$ or $5 \mathrm{~V}$ power and logic, as in Figure 8 [21].

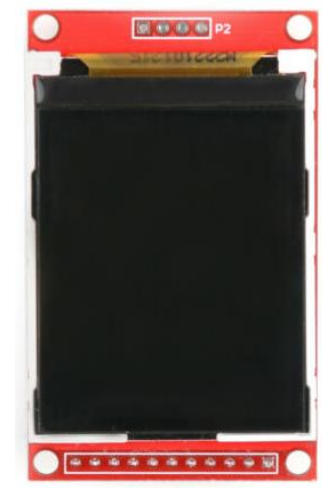

Figure 8: Arduino compatible TFT 2.2 colour screen

\section{The proposed system workflow:}

At first, the main hardware components that include, the TFT colour display and temperature and humidity sensors are initialized. Then, the system frames those dedicated to displaying sensors readings are shown on the colour display. After that, the 
information required to set network connection, those include SSID and PASSWORD are uploaded from the flash memory of the ESP32. Being connected with the Internet, a connection is set to the Blynk server where the readings of the following sensors, soil moisture sensor, tank level sensor and environment temperature and humidity sensor are stored. Upon exceeding the threshold value that was predefined for each sensor, a warning is sent to the person in charge of the field. The person in charge receives those warnings via the BLYNK application which runs on his mobile phone. Using this application, the person who is in chargeable to set the water pump ON/OFF and set the water valve ON/OFF too because not all plants need the same decision. Figure 10 illustrates the system flowchart.

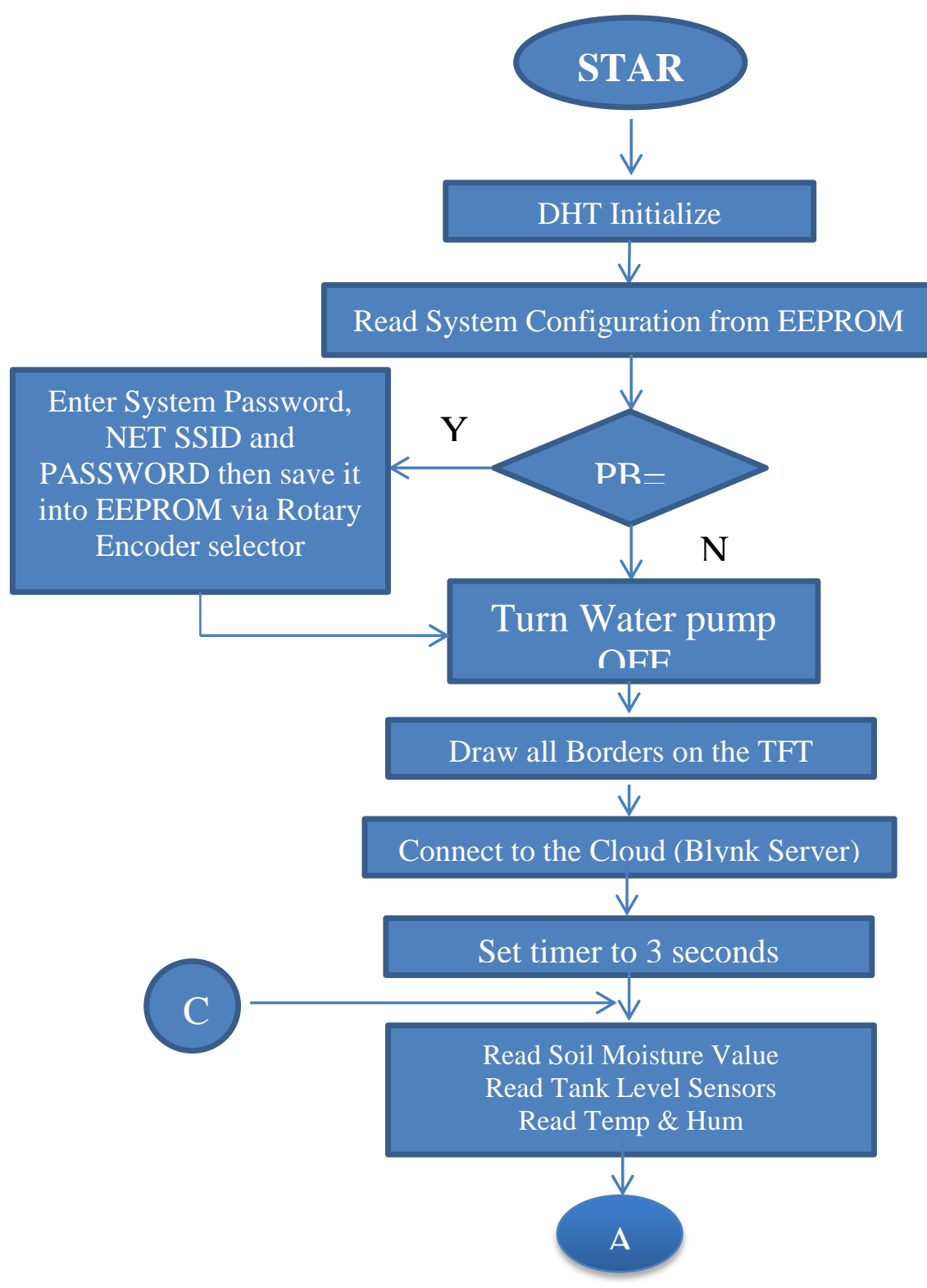




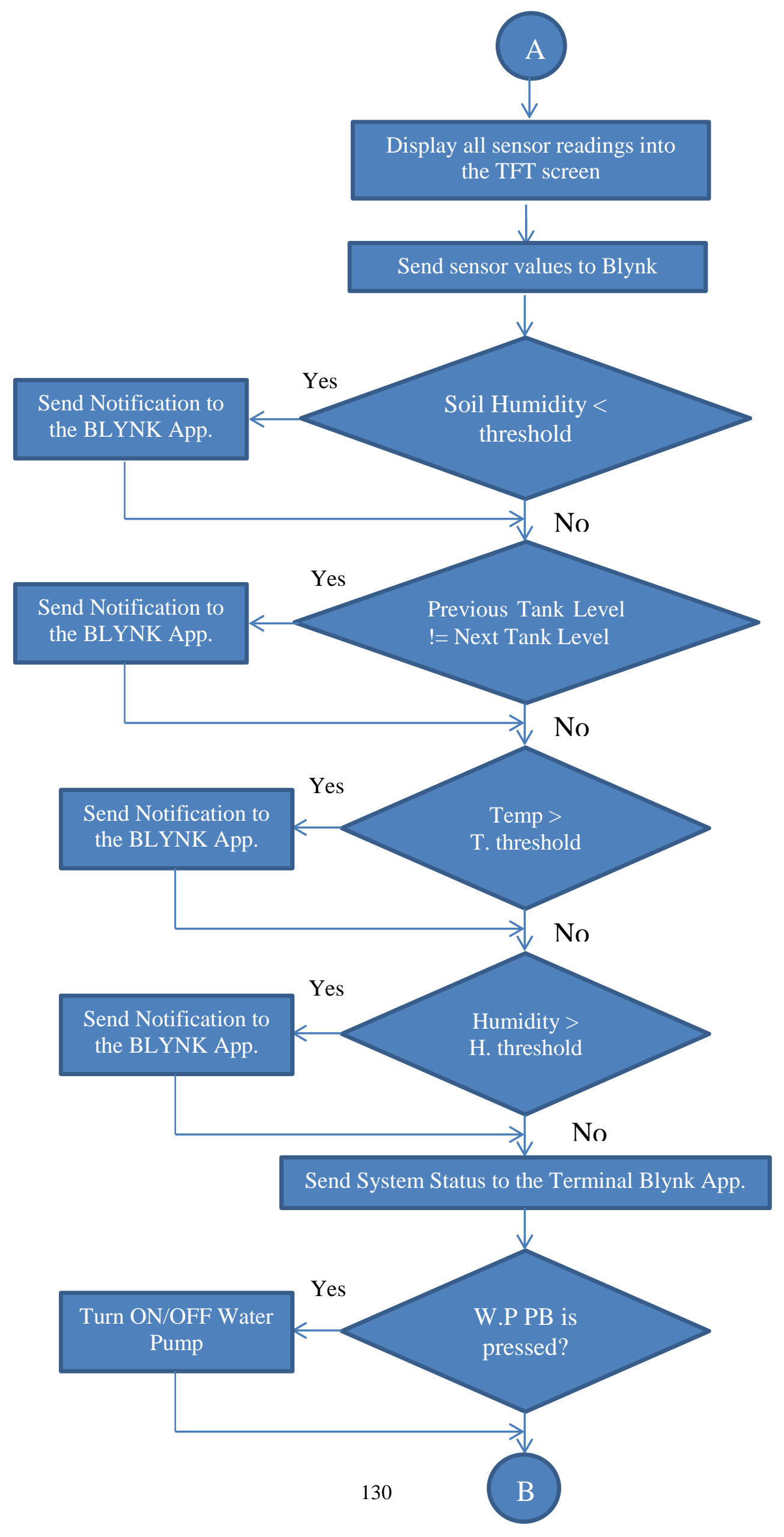




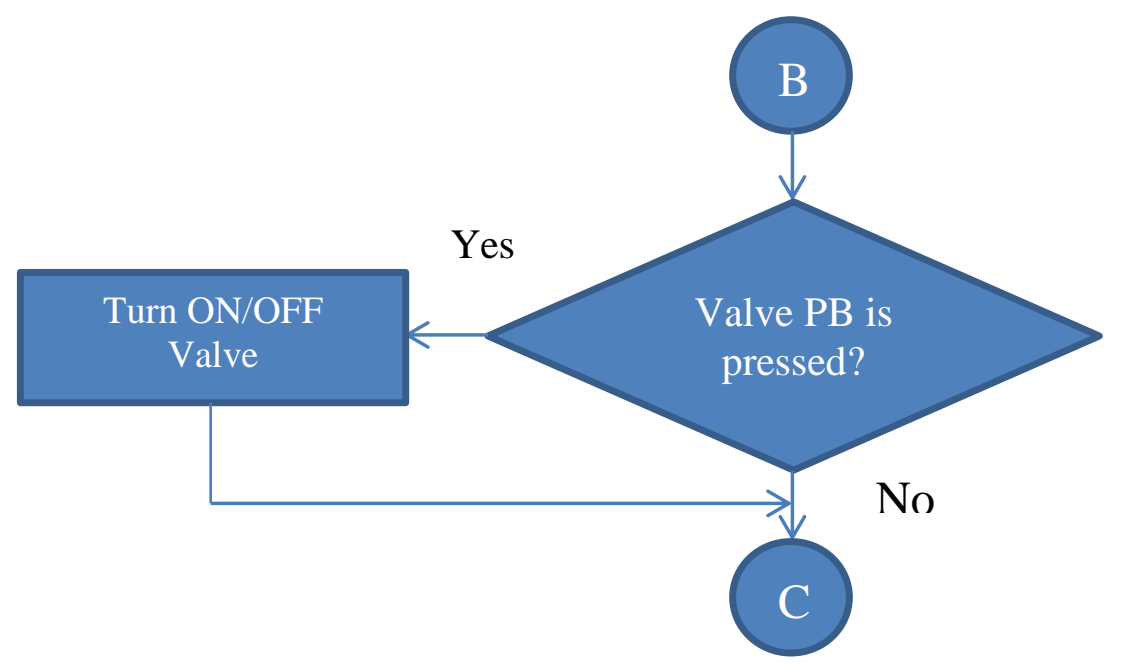

Figure 9: System flowchart

\section{Hardware Implementation}

This section explains in details the way how the physical components are connected. Besides, it also describes the way these components are interfaced with the ports of the ESP32 microcontroller, each according to the working parameters determined in the related library.

Among other existing controller, ESP32 is adopted in the current project to build the system since it is the latest technology of the previous controllers due to its multiple $\mathrm{I} / \mathrm{O}$ ports that are needed, and being fastest in terms of processing and connecting to the Internet.

Figure 10 illustrates the integrated block diagram of the Built System

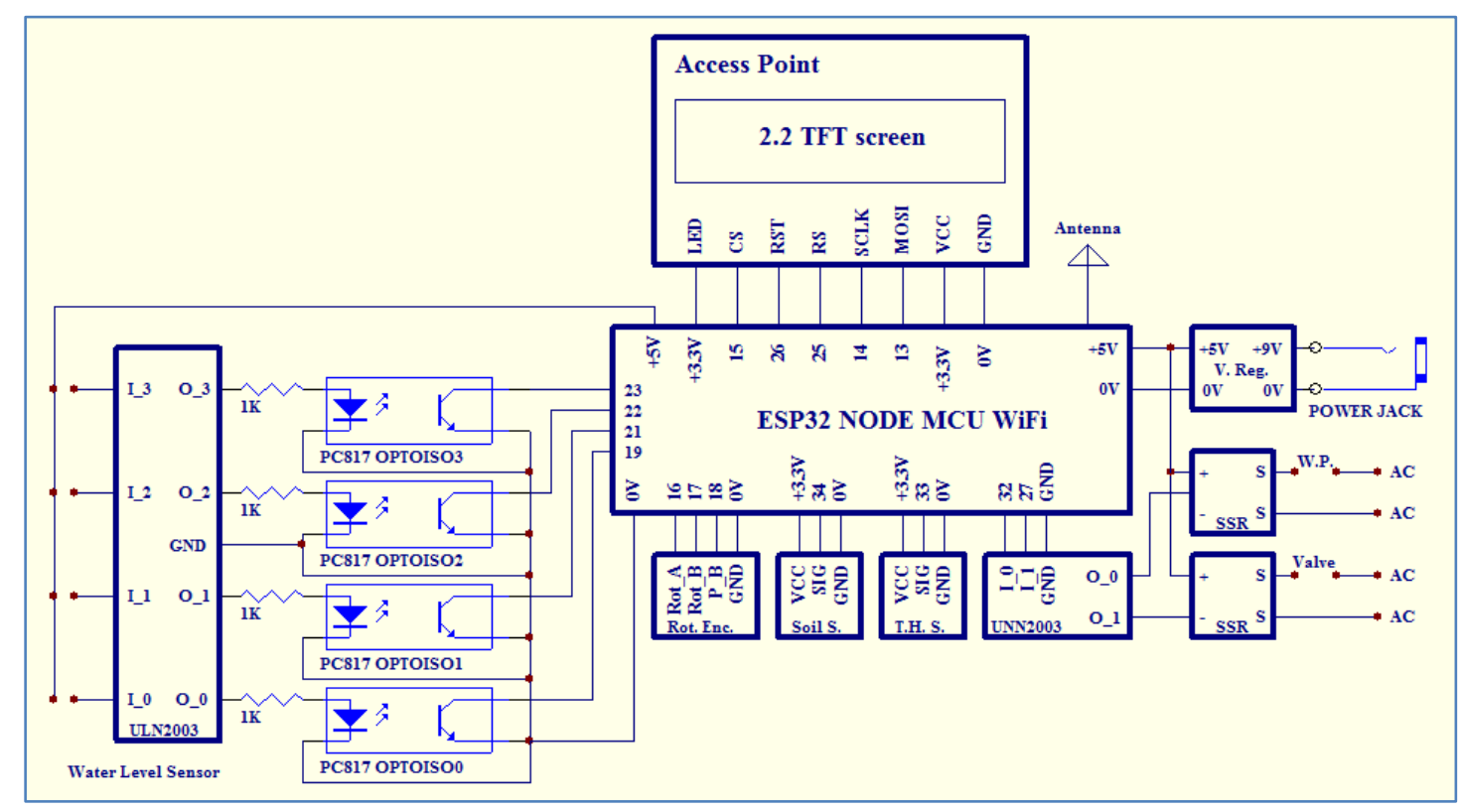

Figure 10: The Integrated Block Diagram of the Built System

\section{Results Discussion}

In this section, most operations are done by using the Blynk application with the designed system, and all widgets are displayed on the Blynk application. Figure 11 
illustrates the designed system while Figures 12-a and 12-b illustrate user-defined Blynk application.

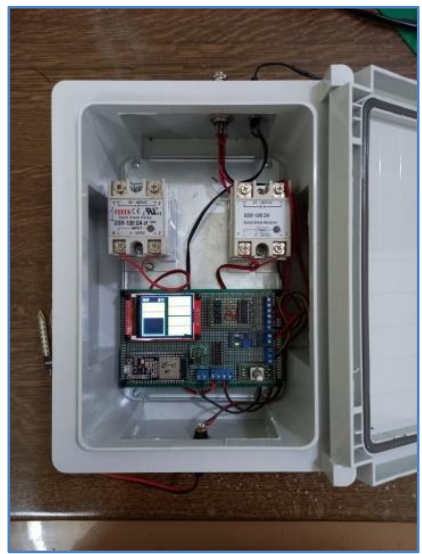

Figure 11: Irrigation System Design

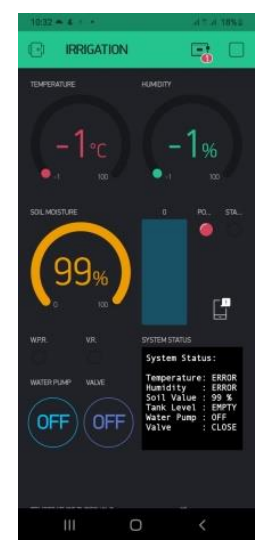

(a)

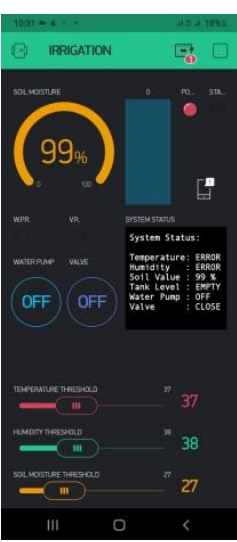

(b)

Figure 12: User-Defined Blynk application

\subsection{Turning Water Pump ON}

By using the button (V10) the water pump can be turned ON/OFF via the Blynk application installed in the Android mobile phone as shown in Figures 13.

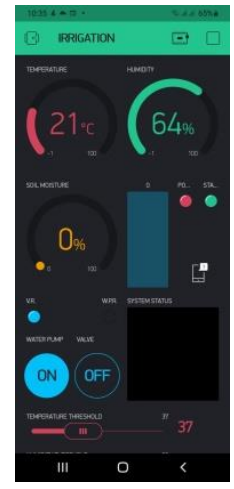

Figure 13: Turning water pump ON 


\subsection{Turning Valve ON}

By using the button (V9) the valve can be turned ON/OFF via the Blynk application installed in the Android mobile phone as shown in Figure 14.

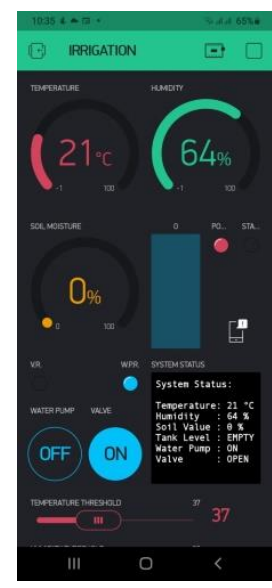

Figure 14: Turning valve pump ON

\subsection{Tank level}

Tank level widget is configured as a (V3) to show the level of water inside the assistant tank, the levels are (Error, 1/4, 1/2, 3/4, Full) with values $(-1,0,1,2,3)$ respectively. Figure 15 illustrates the level of water is equal to $(1 / 4)$.

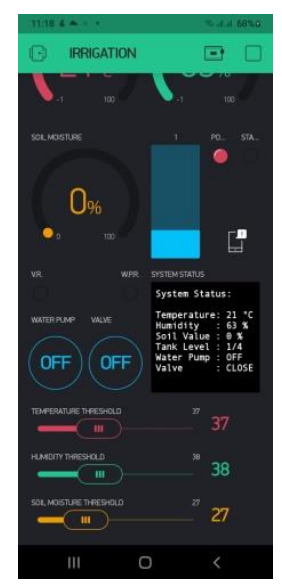

Figure 15: Tank Level is equal to $1 / 4$

\subsection{Temperature and Humidity Gauges}

There are two gauges, one for displaying temperature (V0) and the other for displaying humidity (V1) of the environment. Figure 16 shows that the temperature is equal to (21) and humidity is equal to (63). 


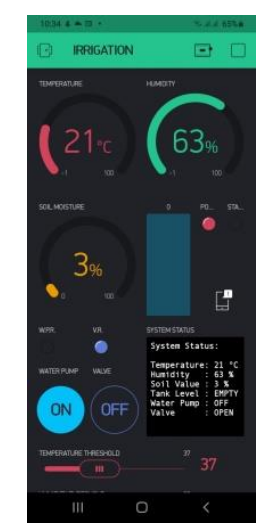

Figure 16: Temperature and Humidity Gauges

\subsection{Soil Moisture Gauge}

The soil moisture level is displayed via soil gauge (V2) with the range between (0-99). See Figure 17 that the value of soil moisture is (32\%).

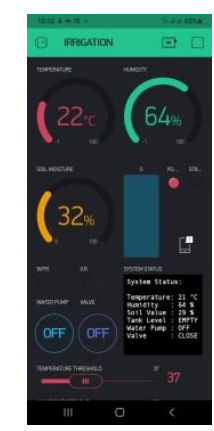

Figure 17: Soil Moisture Gauges

\subsection{Led Indicators}

There are (4) LEDs are used to receive the reply for each command., System status and the valid working system as shown in Figure 18.

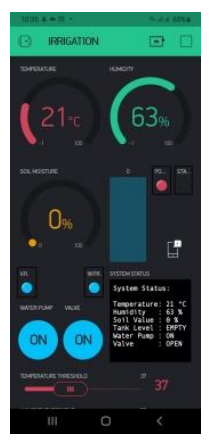

Figure 18: LEDs Indicator

\subsection{Threshold Slides}

There are three slides for (Temperature threshold, Humidity threshold and Soil Moisture Threshold) used (V11, V14. V12, V15. V13, V16) that cause to send a notification when the temperature of the environment reaches more than the temperature threshold when the humidity of the environment reaches more than humidity threshold and the soil moisture value is less than the soil threshold as shown in figure 19. 


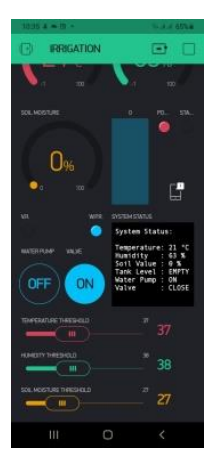

Figure 19: Threshold Slides

\subsection{Terminal Display}

The terminal display (V8) is used to display all system status including Temperature, Humidity, Soil value, Tank level, Water pump status and Valve status as shown in figure 20 .

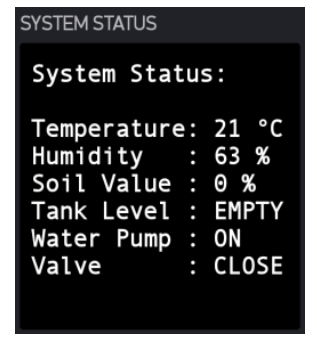

Figure 20: Terminal Display

\subsection{Notification}

Notification widget is used to notify the user when any error or important event occurs, like Tank Level Error, High Temperature, High Humidity, Low Soil value, and any time the current tank level is not equal to the previous.

The error event occurs when any water level sensor is active while the lower is active because it is not logical. See Figure 21.

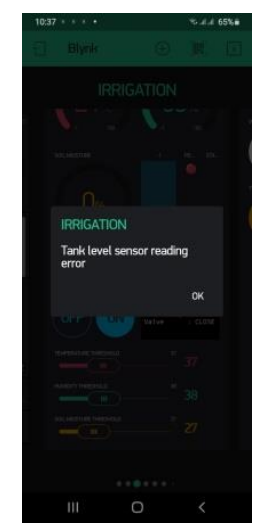

Figure 21: Tank level reading error

\subsection{System Status Display Screen}

The TFT colour screen is used to display all system status in the hardware system part to show the user when he is on the farm as shown in Figure 22. 


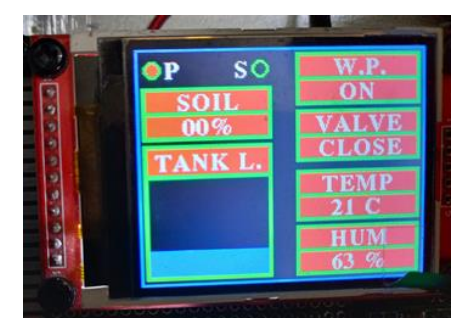

Figure 22: System Status Display Screen

\section{Conclusion and Future Works}

\subsection{Conclusions}

Through the work on the project related to the IoT, the conclusions drawn from it were reached, as indicated by the following points:

- The smart irrigation system implemented is cost-effective for optimizing water resources for agricultural production.

- Through this project, it can be concluded that there can be considerable development in irrigation with those of IoT and automation. Thus this system is a solution to the problems faced in the existing process of irrigation.

- No longer only are farmers able to generally use much less water to grow a crop, they're able to increase growth yields and the satisfaction of the crop by using better management of soil moisture at some point of vital plant growth degrees.

- Embedded system for computerized irrigation of an agriculture subject gives an able solution to assist web page- precise irrigation control that permits producers to maximize their productivity whilst saving the water.

\subsection{Future works}

There are many proposals as future works that add additional features to the project, although it requires a higher cost, as building the project after improvement is largely feasible and can be practically used in the fields of irrigation, including:

- It is possible to increase the area of the environment that is being monitored by adding several soil moisture sensors and increasing the number of microcontrollers, while they can be linked together wirelessly according to a specific topology, such as mesh or star.

- It is possible to use other servers tuned to BLYNK, such as the Think speak server, where the information on the field to be monitored is accessed on the PC through a special webpage for this purpose.

- As future work, it is possible to use the built-in Bluetooth feature within the ESP32, which can be used by entering system parameters instead of using Rotary Encoder, making it easier to physically build the system.

- The region or area wise prediction can be done for giving more accurate farming suggestions of which crop can be grown by analyzing the data based on the soil and weather conditions.

- This paper can further be industrialized with camera feeds for checking the discolouration of leaves or plants and accordingly send the results to control the disease from anywhere.

- The field area can be protected from trespassers by the deployment of AI and surveillance. 


\section{REFERENCES}

[1] Koutroulis A.G., Papadimitriou L.V., Grillakis M.G., Tsanis I.K., Wyser K., Betts R.A.,2017, "Freshwater vulnerability under high-end climate change", A pan-European assessment. Sci. Total Environ. 2018;613:271-286. DOI: 10.1016/j.scitotenv.2017.09.074.

[2] Iglesias A., Santillán D., Garrote L., 2018, “On the barriers to adaption to less water under climate change: Policy choices in Mediterranean countries", Water Resour. Manag. 2018;32:4819-4832. doi: 10.1007/s11269-018-2043-0.

[3] Zampieri M., Carmona García G., Dentener F., Krishna Gumma M., Salamon P., Seguini L., Toreti A., 2002, "Surface freshwater limitation explains worst rice production anomaly in india in 2002", Remote Sens. 2018;10:244. doi: $10.3390 /$ rs 10020244 .

[4] Daskalakis S.N., Goussetis G., Assimonis S.D., Tenzeris M.M., Georgiadis A, 2018, "A uW backscatter-morse_leaf sensor for low-power agricultural wireless sensor networks", IEEE Sens. J. 2018;18:7889-7898. doi: 10.1109/JSEN.2018.2861431.

[5] Guruprasadh J.P., Harshananda A., Keerthana I.K., Krishnan K.Y., Rangarajan M., Sathyadevan S., 2017, "Intelligent Soil Quality Monitoring System for Judicious Irrigation", Proceedings of the 2017 International Conference on Advances in Computing, Communications and Informatics (ICACCI); Udupi, India. 13-16 September 2017.

[6] Parra L., Ortuño V., Sendra S., Lloret J., 2013, "Low-Cost Conductivity Sensor based on Two Coils", Proceedings of the First International Conference on Computational Science and Engineering; Valencia, Spain. 6-8 August 2013.

[7] Sendra S., Parra L., Ortuño V., Lloret L., 2013, “A Low Cost Turbidity Sensor Development", Proceedings of the Seventh International Conference on Sensor Technologies and Applications; Barcelona, Spain. 25-31 August 2013. [Google Scholar]

[8] Gutiérrez Jagüey, J. F. Villa-Medina, A. López-Guzmán and M. Á PortaGándara, 2015, "Smartphone Irrigation Sensor", IEEE Sensors Journal, vol. 15, no. 9, pp. 5122-5127, Sept. 2015.

[9] T. C. Meyer and G. P. Hancke, 2015, "Design of a smart sprinkler system", TENCON 2015 - 2015 IEEE Region 10 Conference, Macao, 2015, pp. 1-6.

[10] Kalezhi, J., et al., 2019, “A DC microgrid smart-irrigation system using internet of things technology”, IEEE PES/IAS PowerAfrica. IEEE, New York (2019).

[11] Das, R.K., Panda, M., Dash, S.S., 2019, "Smart Agriculture System in India Using Internet of Things", Soft Computing in Data Analytics, pp. 247-255. Springer, Singapore (2019).

[12] Espressif, 2017, "Espressif Announces the Launch of ESP32 Cloud on Chip and Funding by Fosun Group". Espressif Systems. 2016-09-07. Retrieved 2017-0331.

[13] "ESP32 Overview", 2016, Espressif Systems. Retrieved 2016-09-01. 
[14] "ESP32 Datasheet" (PDF), 2017, Espressif Systems. 2017-03-06. Retrieved 2017-03-14.

[15] Jim Lindblom, 2016, "Enginursday: First Impressions of the ESP32", Sparkfun Electronics.

[16] Samy Sadeky, Ayoub Al-Hamadiy, Bernd Michaelisy, Usama Sayedz, 2004, "An Acoustic Method for Soil Moisture Measurement", IEEE 2004

[17] https://www.mybotic.com.my/products/FOTEK-40A-Solid-State-Relay-SSR100DA/2464

[18] https://www.amazon.com/Solid-SSR-60DA-SSR-75DA-SSR-100DA-24380V/dp/B07T4NPP4K?th=1

[19] https://components101.com/stepper-motor-driver-ic-uln2003-pinout-datasheet

[20] https://www.electronics-lab.com/wp-content/uploads/2017/10/24-48V-To-5V3A-DC-DC-Converter.pdf

[21] https://forum.arduino.cc/index.php?topic=473378.0, ILI Technology Corp. 